Helgoländer wiss. Meeresunters. 30, 62-75 (1977)

\title{
Changes in specific photosynthetic rate of oceanic phytoplankton from the northeast Pacific Ocean
}

\author{
M. J. HAMEedi \\ Department of Oceanography, University of Washington; \\ Seattle, Washington, USA
}

\begin{abstract}
The study is based on data $(n=244)$ from light-saturation experiments utilizing artificial incubation under fluorescent light. Values of maximum photosynthetic rate, $P_{\max }$, and the light intensity at which it takes place, $I_{\max }$, are estimated by non-linear regression using stepwise Gauss-Newton iterations. Estimated values of $P_{\max }$ ranged from 0.85 to $5.48 \mathrm{mg} \mathrm{C}$ (mg Chl $a \cdot \mathrm{h})^{-1} ; I_{\max }$ varied from 2.35 to $5.52 \mathrm{cal}\left(\mathrm{cm}^{2} \cdot \mathrm{h}\right)^{-1}$. The effects of time (months) and depth (illumination levels) and their interaction are evaluated by analysis of covariance using a linear model. A significant time-depth interaction is noted: The maximum specific primary productivity occurred in the surface layers during March, at the $50 \%$ light level during April, and at $1 \%$ level during May. Estimates of $P_{\max }$ from simulated in situ primary productivity experiments for the same period are lower than those from light-saturation experiments. A comparison of data from light-saturation and simulated in situ experiments indicated that effects of duration of experiments and the quality of available light may affect primary productivity data considerably.
\end{abstract}

\section{INTRODUCTION}

Since Lindeman (1942) generated a model to describe energy flow between various trophic levels, numerous attempts to formulate mathematical models of plankton dynamics have been made. These models have served a useful purpose in attempting to quantify the relatively complex biological phenomena and interactions. In some recent studies, ecosystem modeling has been used as an effective tool for analysis and interpretation of entire ecosystems, such as for the tropical waters (Vinogradov et al., 1972), or for understanding its components, such as nutrient dynamics (Walsh \& Dugdale, 1972), or for resource management purposes, such as in the North Sea (Nihoul, 1975). A severe limitation of simulation studies of plankton dynamics has been the reliability and applicability of some or several of the model coefficients and parameters. The coefficient representing the phytoplankton growth rate, the central process in pelagic ecosystem studies, may be considered as an example. In this paper, an attempt is made to describe the relationship of light and specific photosynthetic rate of oceanic phytoplankton and to assess its variability.

The effect of light on photosynthesis has been studied by various authors, notably 
by Steele (1962), Vollenweider (1965), Bannister (1974) and, more recently, Jassby \& Platt (1976). These authors have attempted to observe general patterns in lightphotosynthesis relationships; the results are presented as simplified mathematical equations. Due to its simplicity, Steele's (1962) equation has been used in several studies on the dynamics of phytoplankton in natural waters (e.g., Taguchi, 1972; Winter et al., 1975).

The results presented herein are based on a large number of data from photosynthesis-light experiments conducted in oceanic waters off the Washington-Oregon coast, USA, in spring 1963 . These data provided a broad basis for analyses by statistical methods to obtain estimates of values of the parameters which provide an adequate fit between an equation and experimental data, and also have physiologically meaningful interpretations.

\section{MATERIAL AND METHODS}

Primary productivity experiments were carried out as a part of a large research programme to provide a description and achieve an understanding of the biological populations and processes in oceanic waters of the northeast Pacific Ocean (Fig. 1). A comprehensive sampling programme to obtain the physical and biological data

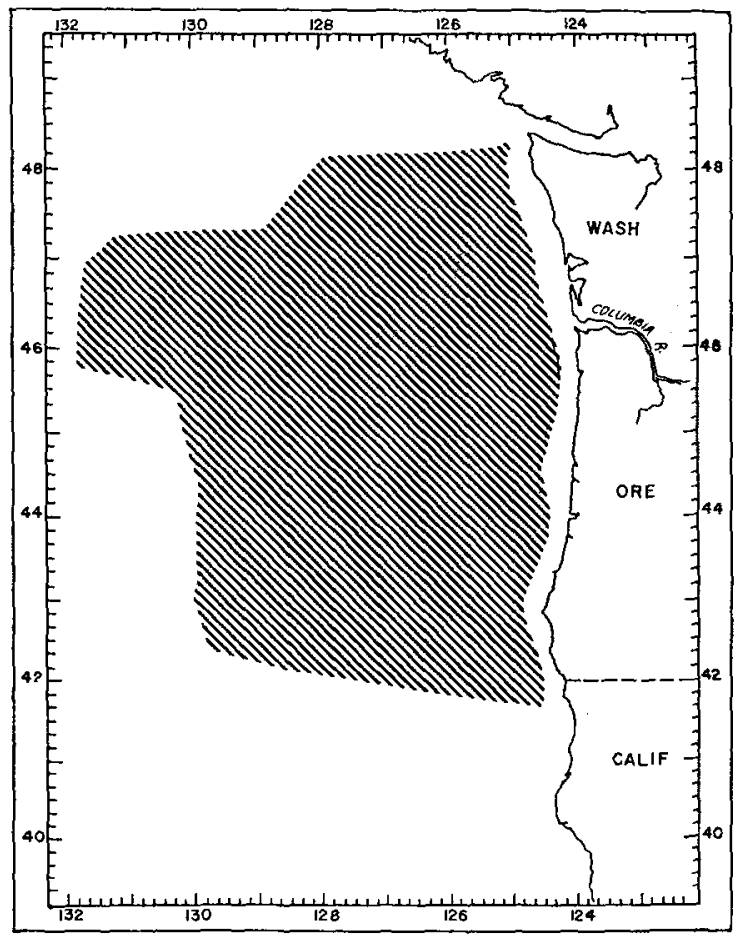

Fig. 1: Research area in the northeast Pacific Ocean 
from various locations in this region was initiated in January 1961 and completed in December 1963. In the year 1963, especially during spring, sampling frequency for biological measurements was most extensive. A detailed description of the physical features of the study area are given by Hameedi (1974). A major factor influencing the seawater salinity and vertical stability in the upper $40 \mathrm{~m}$ of the water column is the freshwater input from the Columbia River at an average of $7,300 \mathrm{~m}^{3} / \mathrm{sec}$ (Barnes et al., 1972). Low salinity water associated with this effluent is identified in the form of a plume in the oceanic regime. A salinity value of 32.5 parts per thousand is used to delineate the plume from the ambient seawater. The nature and extent of variability of various environmental factors, such as temperature, salinity, inorganic plant nutrients, both in the plume and the ambient seawater, are discussed by Hameedi (1976).

\section{Primary productivity}

Water samples were collected with modified Van Dorn PVC (polyvinylchloride) samplers, with a 6 -liter capacity, at depths corresponding to $100,50,10$, and $1 \%$ of the surface illumination. These depths were determined from the computed extinction coefficient from Secchi disc readings. Two types of experiments, light-saturation measurements and simulated in situ measurements of primary productivity were conducted.

\section{Light-saturation experiments}

At each primary productivity station, occupied before noon, samples from one of the sampling depths were incubated at different light intensities to determine lightsaturated rates of photosynthesis by the phytoplankton community. Samples in six light and two dark bottles were inoculated with ${ }^{14} \mathrm{C}$ (approximately 2.5 microcuries) and then incubated for at least two hours in a constant illumination (about $22 \mathrm{klux}$ ) incubator. Illumination was provided by a bank of high-output, cool, white fluorescent lamps. Different levels of illumination were obtained by covering experimental bottles with neutral filters of appropriate densities. Light intensity in the incubator was measured with a Weston sunlight illumination meter, and light energy by a Kahlsico Star pyranometer. The four routine sampling depths were rotated so that each depth was selected for light-saturation experiments.

\section{Simulated in situ experiments}

Samples were prepared as in the light-saturation experiments, but were incubated from local apparent noon to sunset in a topside deck incubator exposed to sunlight. Kodak-Wratten neutral density filters were used to simulate the light levels at 50,10 , and $1 \%$ of the surface illumination. Measurements of incident solar radiation were made continuously with a Kipp and Zonen Solarimeter equipped with a Speedomax circular chart recorder. 
After incubation, each sample was filtered through a HA Millipore filter (pore size, $0.45 \mu \mathrm{m}$ ) and then was stored in the dark in a desiccator.

In the laboratory ashore, filters with ${ }^{14} \mathrm{C}$ tagged phytoplankton were fumed with concentrated hydrochloric acid for 10 to $15 \mathrm{~min}$ to remove traces of inorganic ${ }^{14} \mathrm{C}$. Radioactivity of the filters was measured with a Nuclear-Chicago Model D-47 gas flow counter. At least 1280 counts were obtained for each sample. Data were processed by a computer and corrections were made for background, dark bottle uptake, variation in inorganic carbon content of seawater, coincidence, and isotope effect. Primary productivity values were based on ampoule standardization utilizing the barium carbonate technique. This technique has been reported to yield low rates of photosynthesis (Steemann Nielsen, 1965); however, no corrections have been made for this effect in the data presented here.

\section{Chlorophyll a}

A portion (2-3 1) of the same water sample obtained for primary productivity measurements was filtered through a HA Millipore filter (pore size, $0.45 \mu \mathrm{m}$ ) with the addition of magnesium carbonate powder. Unused edges of the filters were removed and the filters were stored in a desiccator. In the shore laboratory each filter was ground with a plastic tissue grinder and the chlorophyll as extracted in $90 \%$ acetone. The extract was centrifuged and then the supernatant analyzed for plant pigments.

Concentration of chlorophyll $a$ was determined by the spectrophotometric method of Richards with Thompson (1952) as modified by Creitz \& Richards (1955). As this procedure gave considerable higher estimates of chlorophyll $a$ than the method recommended (Banse \& Anderson, 1967), all chlorophyll $a$ data was revised utilizing Unesco equations (Unesco, 1966). Estimates of chlorophyll were not corrected for phaeopigments.

\section{DATA AND STATISTICAL ANALYSES}

Photosynthesis data from experiments described in this paper are presented as specific photosynthetic rate, $\mathrm{mg} \mathrm{C}\left(\mathrm{mg} \mathrm{Chl} a \cdot \mathrm{h}^{-1}\right.$, and light intensity as cal $\left(\mathrm{cm}^{2} \cdot \mathrm{h}\right)^{-1}$. A detailed listing of these data were given by Hameedi (1974). Preliminary examination of photosynthesis-light curves for individual experiments showed a consistent, but not always a large, reduction in photosynthetic rate at high light intensities. Steele's (1962) equation, due to its simplicity and apparent applicability to data, was used to estimate values of parameters describing the relationship between incident light and photosynthesis in the northeast Pacific Ocean. According to this equation, the relationship between light intensity, $I$, and rate of photosynthesis, $P$, is expressed as follows:

$$
P=P_{\max } I / I_{\max } e^{\left(1-I / I_{\max }\right)}
$$

The parameters, $P_{\max }$ and $I_{\max }$, represent the maximum photosynthesis rate and the optimal light intensity for the maximum photosynthetic rate, respectively. 
Values of the two parameters were estimated by non-linear regression using stepwise Gauss-Newton iterations. According to this method, if incident radiation, $I$, is the input variable and $Y$ denotes primary productivity, and

$$
Y=f\left(I ; P_{\max } \text { and } I_{\max }\right)+\varepsilon
$$

then the sum of squares of differences between the observed and computed values, $\Sigma(Y-f)^{2}$ is minimized as a function of the parameters (Hartley, 1961). All computations were made by using BMD-X85 program of the Health Sciences Computing Facility, University of California, Los Angeles (Dixon, 1970).

The effect of time (months), depths (illumination levels), and timedepth interaction were analyzed by analysis of covariance using a general linear model. Linear transformation of Equation 1 results in the following form

$$
\ln P=\ln \frac{P_{\max }}{I_{\max }}+\ln I+1-\frac{I}{I_{\max }}
$$

Denoting $\ln P$ as $Y ; \ln \left(P_{\max } / I_{\max }\right)+1$ as $\alpha ;-1 / I_{\max }$ as $\gamma ; \ln I$ as $X_{1}$; and $I$ as $X_{2}$ the following familiar model is obtained

$$
Y=\alpha+X_{1}+\gamma X_{2}
$$

It should be noted that the value of the regression coefficient for $X_{1}, \beta$, is unity. According to the covariance model, $Y$ has normal distribution with a mean equal to $\alpha+X_{1}+\gamma X_{2}$, and unknown variance. Thus for the $\mathrm{kth}$ observation we have the following

$$
Y_{\mathrm{k}}=\alpha+X_{1 \mathrm{k}}+\gamma X_{2 k}+\varepsilon_{k}
$$

where $\varepsilon_{k}$ is the error term and is normally distributed $\left(\mathrm{O}, \sigma^{2}\right)$.

The effect of time, depth, and time-depth interaction was then included in the model, equation 4 , by adding appropriate parameters.

$$
Y_{i j k}=T_{i}+D_{j}+(T D)_{i j}+\alpha+X_{1 i j k}+\gamma X_{2 i j k}+\varepsilon_{i j k}
$$

In this model, observation $Y$ is now classified according to time $(i=1,2,3)$, and depths $(j=1,2,3,4)$. Computations were made by the BMD-X64 computer programme of the Health Sciences Computing Facility, University of California, Los Angeles (Dixon, 1970). 'The following null hypotheses were tested:

$$
\begin{aligned}
& H_{1}: T D_{\mathrm{ij}}=0, \text { and } \beta=1 \\
& H_{2}: T D_{\mathrm{ij}}=0, T_{i}=0, \text { and } \beta=1 \\
& H_{3}: T D_{\mathrm{ij}}=0, D_{j}=0, \text { and } \beta=1 \\
& H_{4}: \beta=1
\end{aligned}
$$

Due to the lack of sufficient observations, the effect of locations (Columbia River plume and ambient seawater) was not included in the model.

\section{RESULTS}

The estimated values of the parameters of Equation 1, $P_{\max }$ and $I_{\max }$, from light-saturation experiments are presented in Table 1 . It will be noted that there was considerable variability in the values of both parameters. In general, $P_{\max }$ values 
Table 1

Estimated values and standard deviations for $P_{\max }, \mathrm{mg} \mathrm{C}(\mathrm{mg} \mathrm{Chl} a \cdot \mathrm{h})^{-1}$, and $I_{\max }$, cal $\left(\mathrm{cm}^{2} \cdot \mathrm{h}\right)^{-1}$, from light-saturation experiments. Sampling depths (percent of surface illumination) and number of observations (in parentheses) are also given

\begin{tabular}{|cccccccc}
\hline Months & $P_{\max }$ Plume & $I_{\max }$ & $(\mathrm{n})$ & $P_{\max }$ & $I_{\max }$ & $(\mathrm{n})$ \\
\hline March & & & & & & & \\
$100 \%$ & $4.46 \pm 1.49$ & $6.15 \pm 4.31$ & $(12)$ & $1.68 \pm 0.25$ & $3.60 \pm 1.52$ & $(6)$ \\
$50 \%$ & $2.63 \pm 0.27$ & $4.23 \pm 0.98$ & $(9)$ & $2.48 \pm 0.23$ & $5.31 \pm 1.18$ & $(12)$ \\
$10 \%$ & $1.91 \pm 0.48$ & $4.20 \pm 2.75$ & $(12)$ & $1.88 \pm 0.11$ & $3.12 \pm$ & 0.49 & $(6)$ \\
$1 \%$ & $2.42 \pm 0.13$ & $3.98 \pm 0.58$ & $(16)$ & $1.46 \pm 0.18$ & $3.36 \pm 1.19$ & $(10)$ \\
April & & & & & & & \\
$100 \%$ & $2.39 \pm 0.17$ & $6.14 \pm 0.88$ & $(18)$ & $1.17 \pm 0.15$ & $3.30 \pm 1.05$ & $(12)$ \\
$50 \%$ & $1.91 \pm 0.09$ & $5.54 \pm 0.59$ & $(6)$ & $2.03 \pm 0.18$ & $6.27 \pm 1.14$ & $(18)$ \\
$10 \%$ & $2.08 \pm 0.06$ & $3.44 \pm 0.23$ & $(6)$ & $1.48 \pm 0.15$ & $5.00 \pm 1.17$ & $(12)$ \\
$1 \%$ & $0.85 \pm 0.11$ & $2.35 \pm 0.59$ & $(18)$ & $1.16 \pm 0.05$ & $3.45 \pm 0.33$ & $(12)$ \\
May & & & & & & & \\
$100 \%$ & $1.99 \pm 0.43$ & $6.61 \pm 2.88$ & $(12)$ & $5.48 \pm 3.13$ & $15.52 \pm 11.53$ & $(12)$ \\
$50 \%$ & $1.83 \pm 0.21$ & $6.49 \pm 1.43$ & $(12)$ & & $*$ & & $*$ \\
$10 \%$ & & $*$ & & $2.43 \pm 0.60$ & $2.51 \pm 1.35$ & $(17)$ \\
$1 \%$ & $*$ & $*$ & & & & & \\
$*$
\end{tabular}

Table 2

Estimated values and standard deviations for $P_{\max }, \mathrm{mg} \mathrm{C}(\mathrm{mg} \mathrm{Chl} a \cdot h)^{-1}$, and $I_{\max }$, cal $\left(\mathrm{cm}^{2} \cdot \mathrm{h}\right)^{-1}$, from light-saturation experiments. (The effect of illumination levels is not considered)

\begin{tabular}{|ccc|}
\hline Months & $P_{\max }$ & $I_{\max }$ \\
\hline March & & \\
Plume & $2.63 \pm 0.24$ & $4.15 \pm 0.96$ \\
Ambient & $1.88 \pm 0.11$ & $3.94 \pm 0.68$ \\
April & $1.65 \pm 0.15$ & $4.52 \pm 1.00$ \\
Plume & $1.48 \pm 0.09$ & $4.65 \pm 0.64$ \\
Ambient & $1.93 \pm 0.24$ & $6.66 \pm 1.66$ \\
May & $2.47 \pm 0.42$ & $4.03 \pm 1.66$ \\
Plume & & \\
Ambient & & \\
\hline
\end{tabular}

were lower than values reported in the literature. Maximum production rates were noted for the surface layer in the plume during March, and in ambient seawater during May. During March, maximum production rates were generally higher in the plume, but the difference between the plume and ambient seawater was small during April. A similar comparison for May values is limited due to the lack of observations in some categories. However, if the depth effect is not considered (Table 2), the average maximal production rate was higher in ambient seawater than in the plume in May. The significance of this difference is reduced by relatively large standard deviations for the estimates.

Effects of months and illumination levels were tested by the analysis of covariance 
Table 3

Analysis of covariance table for primary productivity data from light-saturation experiments. (See text for details)

\begin{tabular}{|lcccc|}
\hline \multicolumn{1}{|c}{ Source } & $\begin{array}{c}\text { Sum of } \\
\text { squares }\end{array}$ & $\begin{array}{c}\text { Degrees of } \\
\text { freedom }\end{array}$ & $\begin{array}{c}\text { Mean } \\
\text { square }\end{array}$ & $\begin{array}{c}\text { Variance } \\
\text { ratio, } F\end{array}$ \\
\hline Time (months) & 3.28 & 2 & 1.64 & \\
Depths (illumination levels) & 0.59 & 3 & 0.20 & \\
Time X depth & 2.60 & 6 & 0.43 & \\
$\quad$ interaction & & & & \\
$\quad$ hypothesis 1 & 231.64 & 7 & 33.09 & \\
$\quad$ hypothesis 2 & 235.77 & 9 & 26.20 & \\
$\quad$ hypothesis 3 & 233.50 & 10 & 23.35 & \\
$\quad$ hypothesis 4 & 228.04 & 1 & 228.04 & \\
Covariances & 122.92 & 2 & 61.46 & $107.03 * *$ \\
Cov. 1 (ln I) & 80.80 & 1 & 80.80 & $140.71 \% *$ \\
Cov. 2 (I) & 30.75 & 1 & 30.75 & $53.55^{* *}$ \\
Error & 132.07 & 230 & 0.57 & \\
*\% Denotes significance at 1\% level & & & \\
\hline
\end{tabular}

(Table 3 ). Both covariates, 1 I I and I, were found to be highly significant. The residual mean square of error to test hypothesis 1 (No time $\times$ depth interaction, and $\beta=1$ ) was calculated by adding the sum of squares for error term and for hypothesis 4 $(\beta=1)$, and then dividing the sum by the combined degress of freedom. Variance ratio, $F$, to test hypothesis 1 ,

$$
H_{1}: F=\frac{33.09}{1.56}=21.21 \%
$$

Table 4

Estimated values and standard deviations for $P_{\max }, \mathrm{mg} \mathrm{C}(\mathrm{mg} \mathrm{Chl} a \cdot \mathrm{h})^{-1}$, and $I_{\max }$, cal $\left(\mathrm{cm}^{2} \cdot \mathrm{h}\right)^{-1}$, from light-saturation experiments. (The effect of location - plume, ambient seawater - is not considered)

\begin{tabular}{|rcc|}
\hline Months & \multicolumn{1}{c|}{$P_{\max }$} & $I_{\max }$ \\
\hline March & & \\
$100 \%$ & $3.48 \pm 1.08$ & $5.76 \pm 3.93$ \\
$50 \%$ & $2.49 \pm 0.16$ & $4.60 \pm 0.73$ \\
$10 \%$ & $1.90 \pm 0.29$ & $3.86 \pm 1.59$ \\
$1 \%$ & $2.05 \pm 0.15$ & $4.03 \pm 0.84$ \\
April & $1.82 \pm 0.18$ & $4.84 \pm 1.13$ \\
$100 \%$ & $2.00 \pm 0.13$ & $6.10 \pm 0.82$ \\
$50 \%$ & $1.65 \pm 0.14$ & $4.20 \pm 0.90$ \\
$10 \%$ & $0.96 \pm 0.07$ & \\
$1 \%$ & & $7.70 \pm 3.03$ \\
May & $2.75 \pm 0.60$ & $6.51 \pm 1.43$ \\
$100 \%$ & $1.83 \pm 0.21$ & $2.52 \pm 1.36$ \\
$50 \%$ & $2.43 \pm 0.60$ & $8.87 \pm 3.22$ \\
$10 \%$ & $2.90 \pm 0.66$ & \\
$1 \%$ & &
\end{tabular}


shows a highly significant interaction: critical value of $F$ at $1 \%$ level is $2.72(7,231$ degrees of freedom). Because of the significance of this interaction, variance ratios for main effects of months and depths were not calculated. The time $x$ depth interaction is also quite obvious from Table 4 in which location effect is not considered. According to the table, maximum average production rates occurred in the surface layers during March, at the 50\% illumination level during April, and at $1 \%$ illumination level during May.

Estimated values of $P_{\max }$ and $I_{\max }$ from simulated in situ experiments are presented on an hourly basis (Table 5) using average number of hours of daylight

Table 5

Estimated values and standard deviations for $P_{\max }, \mathrm{mg} \mathrm{C}(\mathrm{mg} \mathrm{Chl} a \cdot \mathrm{h})^{-1}$, and $I_{\max }$, cal $\left(\mathrm{cm}^{2} \cdot \mathrm{h}\right)^{-1}$, from simulated in situ experiments

\begin{tabular}{|ccc|}
\hline Months & $P_{\max }$ & $I_{\max }$ \\
\hline March & & \\
Plume & $1.43 \pm 0.19$ & $7.85 \pm 2.55$ \\
Ambient & $1.32 \pm 0.11$ & $6.66 \pm 1.11$ \\
April & $1.10 \pm 0.10$ & $10.78 \pm 2.29$ \\
Plume & $1.10 \pm 0.09$ & $11.15 \pm 2.06$ \\
Ambient & $1.08 \pm 0.12$ & $19.45 \pm 5.08$ \\
May & $0.81 \pm 0.11$ & $17.05 \pm 6.23$ \\
Plume & & \\
Ambient & & \\
\hline
\end{tabular}

(Nautical Almanac 1963) to compare them with values for March, April, and May from light-saturation experiments (Table 2). $P_{\max }$ values from simulated in situ experiments were considerably lower than from light-saturation experiments. A slightly higher production rate was noted in the plume during March and May; in April values for the plume and ambient seawater were similar.

Estimated values of $I_{\max }$ from simulated in situ experiments were generally higher than those from light-saturation experiments, especially for April and May. $I_{\max }$ values for May have large standard deviations, probably because of the small number of observations. When the location effect was not considered for the data from May, the revised values of $I_{\max }$ from simulated in situ experiments were found to be $16.06 \pm 3.17 \mathrm{cal}\left(\mathrm{cm}^{2} . \mathrm{h}\right)^{-1}$. No such reduction in the standard deviation of estimates was noted for data from March or April.

\section{DISCUSSION}

\section{Maximumspecific photosynthetic rate}

The maximum ratio between photosynthetic rate and chlorophyll $\alpha$ concentration, $P_{\max }$, is often called the assimilation ratio or assimilation number of the phytoplankton population. The following two values of assimilation ratios have been referred to 
in the literature frequently: $3.7 \mathrm{mg} \mathrm{C}(\mathrm{mg} \mathrm{Chl} \alpha . \mathrm{h})^{-1}$ (Ryther \& Yentsch, 1957), and $4 \mathrm{mg} \mathrm{C}$ ( $\mathrm{mg} \mathrm{Chl} \alpha \cdot \mathrm{h})^{-1}$ (Strickland, 1960). However, available literature data on the subject and the results of experiments reported herein show a large range of values. Ryther \& Yentsch (1957) reported values from 2 to 6 for freshwater and marine phytoplankton; for phytoplankton in the North Sea, Steele \& Baird (1961) found values between 0.7 to 1.7. For waters off the coasts of Washington and Oregon, Anderson (1964) showed large variability in $P_{\max }$ values obtained from surface water samples, but reported that $P_{\max }$ values were lower in oceanic areas. For neritic waters along the Oregon coast, Curl \& Small (1965) observed a range from 6 to 20 over a period of two years. In view of the above estimates, it follows that there is no specific value for carbon assimilation per chlorophyll $\alpha$ at optimal light intensity; therefore it seems unrealistic to use averaged values from different seasons and locations in estimating productivity of a given area. Furthermore, in this study, analysis of covariance showed a highly significant month $\times$ depth interaction; therefore, data of different months or depths cannot be combined to obtain an average value. The estimates of $P_{\max }$ from light-saturation experiments (Table 1), showed that during March and April the maximum specific production rate in ambient seawater occurred at the $50 \%$ illumination level and in the plume at the $100 \%$ level. This pattern for the ambient and plume regimes indicates presence of "non-light adapted" and "light adapted" phytoplankton, respectively (Ryther \& Menzel, 1959). A similar pattern in the plume and ambient seawater was noted by Anderson (1972) in winter. The difference on light adaptation is probably due to the earlier stabilization of the water column in the plume (Anderson, 1964) which would have exposed the phytoplankton in the plume to more sunlight. In ambient seawater, at the same time, vertical mixing would have carried phytoplankton into deeper layers.

It is quite obvious that the effects of illumination levels and months alone cannot explain the changes in $P_{\max }$ values in the data treated herein. Species composition or, at least, the relative abundance of major groups of phytoplankton might be important, although Dunstan (1973) did not find significantly different photosynthesis-light intensity curves among five species representing different groups of marine phytoplankton.

\section{Light-saturation and simulated in situ measurements}

For numerous reasons, comparison of productivity rates from laboratory incubation and in situ measurements is a difficult task. In one of the few such studies, Talling (1960) showed that agreement between laboratory and in situ measurement of light saturated rate of photosynthesis, expressed per unit cell volume per hour, of a laboratory grown diatom was fairly good. In his study, field exposures were of a short duration, one to one and one-half $h$, and the difference between the laboratory light source (2100-2500 lux in text, and about $25 \mathrm{klux}$ in diagrams) and sunlight intensity was large. $P_{\max }$ values from the two sets of experiments reported herein, light-saturation and simulated in situ, are in fair agreement with values in the lower 
range reported by Anderson (1964) for the area. Values from simulated in situ measurements (Table 5) were generally lower than those from light saturation experiments (Table 2). However, the following points should be considered when making such comparisons:

(1) The quality of light for the two sets of experiments was different. Unfortunately, neither approximates the distribution of light in seawater under natural conditions. There is now substantial evidence that different parts of the light spectrum of the same intensity have different effects on the concentration of chlorophyll and the photosynthetic rate of laboratory grown and natural populations of phytoplankton (Wallen \& Geen, 1971; Steemann Nielsen \& Willemöes, 1971).

(2) Duration of experiments: Light saturation experiments were conducted for two to four hours, whereas simulated in situ experiments lasted for one-half day. Short-term experiments have the disadvantage that extrapolation of daily production is very imprecise, since periodicity in photosynthesis and chlorophyll concentration could cause serious errors in the estimation of primary productivity (Curl \& Small, 1965; Small et al., 1972; Glooschenko et al., 1972). Also, as chlorophyll measurements were made prior to incubation, primary productivity rate would be considerably overestimated in simulated in situ experiments when substantial growth occurs. Furthermore, the initial release of unlabelled organic carbon from cells during the course of an experiment (Anderson \& Zeutschel, 1970) could lead to overestimates of particulate primary production.

(3) Light intensity above the optimum value has the effect of reducing the primary productivity rate by photoinhibition (Steemann Nielsen, 1962) or by photorespiration (Harris \& Lott, 1973). Phytoplankton contained in experimental bottles exposed to full sunlight for half a day is, therefore, likely to show low production rates, whereas in the sea, a given phytoplankton cell is unlikely to remain near the surface for such a long time.

(4) $P_{\max }$, estimated from simulated in situ experiments, incubated from local noon to sunset, would be underestimated due to the expected higher initial production rates. The bias thus introduced would be related to the distribution of sunlight during the incubation period, as the instantaneous rate of phytoplankton would be continually changing with time of the day. On a clear, bright day surface $P_{\max }$ values could be underestimated by a factor approximately equal to $\pi / 2$ (Dr. D. F. Winter, personal communication; also see Vollenweider, 1965).

\section{Optimallight intensity}

Estimated values of $I_{\max }$ from laboratory incubation experiments presented herein are not widely different from each other, except for surface layers in ambient seawater in May where a high value and large variability was noted. Most of the values presented in Table 1 are fairly close to the often-quoted average for marine phytoplankton - 2000 foot-candles, or approximately $0.1 \mathrm{cal}\left(\mathrm{cm}^{2}\right)^{-1}$ or langley per minute. Values for optimal light intensity have been reported to be different for different groups of phytoplankton. Ryther (1956) gave the following $I_{\max }$ values: 1.74 
langleys per hour for Chlorophyta, 4.62 langleys per hour for diatoms, and 9.66 langleys per hour for dinoflagellates. Variations in $I_{\max }$ values reported herein (Table 1) could also be due to difference in composition of the phytoplankton.

In contrast, simulated in situ experiments show progressively higher values of $I_{\max }$ from March to May (Table 5). This could be due to increasingly higher light intensities at which the cells were growing. It has been shown by several workers that $I_{\max }$ depends on the light intensity at which a population was reared and occursclose to the "pre-conditioning" light intensity (e.g., Strickland, 1965). Estimated values of $I_{\max }$ were, nevertheless, lower than the maximum available solar radiation in these months: 14, 18, and 22 langleys per hour for March, April, and May, respectively.

The divergence between the two sets of values of $I_{\max }$ may also be due to the low maximum intensity of available light in the incubator. The incubator used in light-saturation experiments had a maximum light intensity of about 22 klux (equivalent to about 0.1 langleys per minute), a value much lower than the maximum value expected in nature. Incubators used by other workers have similar low maximum energy output: 25 klux? (Talling, 1960), 9 klux (Anderson, 1964), and $30 \mathrm{klux}$ (Taguchi, 1972). The apparent difference in $I_{\max }$ values from the two types of experiments reported herein does not indicate a difference in the physiological or biochemical response of phytoplankton, but points mainly toward the inadequate intensity of light during laboratory incubation. The effect of the incubator light intensity on the estimates of $P_{\max }$ values, as distinct from the other factors discussed previously, cannot be ascertained.

\section{Covariance mode 1}

With the widespread use of electronic computers, statistical analysis of ecological data has become common in recent years. Inferences and results from multivariate analysis applied to ecological data have provided useful insights and interpretations of observed distribution of organisms (e.g. Stevenson et al., 1974), environmental parameters (e.g. Wikum \& Wali, 1974), and biological processes (e.g. Hameedi, 1976). The analysis of covariance described in this paper is one of the very few such attempts to analyze primary productivity data. The highly significant interaction between the effects of illumination levels and months did not permit the averaging of data over these factors. Interaction between environmental or experimental factors, even though difficult to explain quantitatively, is almost always present and should be expected, i.e., it should be included in statistical models. In experimental biological research it is frequently expressed as synergism or interference of variables (Sokal \& Rohlf, 1969). The interaction noted in this study is biologically explainable and has meaningful interpretations.

A slightly different covariance model was applied to summer primary productivity data from the Arctic Ocean by Smith \& English (unpublished data). They noted that the effect of time $(i=1,2,3)$ was highly significant and that the effect of depth $(j=1,2)$ was not significant. Estimated values of $P_{\max }$ for the three time periods June 15 to August 1, August 2 to August 20, August 21 to September 20, 1971 - were 
7.2, 5.8, and $3.6 \mathrm{mg} \mathrm{C}(\mathrm{mg} \mathrm{Chl} a . \mathrm{h})^{-1}$, respectively. The potential applicability of such analyses is wide as several other factors, such as temperature, heavy metal or hydrocarbon concentration, can easily be added to the covariance model to assess their significance. It should be emphasized that the obtained results be evaluated in light of the assumptions inherent in the model and the applicability of Steele's (or any other) equation to the data. From the biological point of view, it should be noted that significant changes in $P_{\max }$ values with time may simply be the result of changes in the mass to chlorophyll ratio in phytoplankton cells as photosynthesis data are incorporated as $\mathrm{mg} \mathrm{C}$ assimilated per $\mathrm{mg} \mathrm{Chl} a$ per hour.

\section{CONCLUSIONS}

The problem of quantifying the effect of light on primary productivity may require further examination and possibly a reevaluation of existing concepts. A general pattern of the relationship between light and photosynthesis of phytoplankton is well defined. However, the problem of the interpretation of different types of experimental data and results (from short-term experiments, with an artificial light source, 24-h incubations, etc.) and their application to natural conditions is still unresolved.

The discussion of problems outlined in this paper is based on historic data. Nonetheless, similar data are still routinely obtained in most field ecological programmes to assess physiological response or productivity potential of phytoplankton. Extensive new data are needed to gain a thorough understanding of the dynamics of phytoplankton productivity. It may become necessary to distinguish the effects of light, temperature, and nutrient concentrations in the medium from those of cellular nutrient pools, and pigment and enzyme concentrations of phytoplankters. Once the objectives are clarified, experimental design and sampling strategy should be formulated. A variety of statistical procedures are available to analyze the resulting data.

Acknowledgements. Financial support for the research reported in this paper was provided by research contracts from the U.S. Atomic Energy Commission, AT-(45-1) 2225 (RLO2225-T26-49), and the Office of Naval Research, U.S. Navy, N-00014-67-A-00014 Project NR 083 012. Contribution No. 933 from the Department of Oceanography, University of Washington, Seattle. By acceptance of this article, the publisher and/or recipient acknowledges the U.S. Government's right to retain a nonexclusive, royalty-free license in and to any copyright covering this paper.

\section{LITERATURE CITED}

Anderson, G. C., 1964. The seasonal and geographic distribution of primary productivity off the Washington and Oregon coasts. Limnol. Oceanogr. 9, 284-302.

- 1972. Aspects of marine phytoplankton studies near the Columbia River, with special reference to a sub-surface chlorophyll maximum. In: The Columbia River estuary and adjacent ocean waters: bioenvironmental studies. Ed. by A. T. Pruter \& D. L. Alverson. Univ. of Washington Press, Seattle, 219-240.

- \& Zeutschel, R. P., 1970. Release of dissolved organic matter by marine phytoplankton in coastal and offshore areas of the northeast Pacific Ocean. Limnol. Oceanogr. 15, 402-407. 
Bannister, T. T., 1974. Production equations in terms of chlorophyll concentrations, quantum yield, and upper limit to production. Limnol. Oceanogr. 19, 1-12.

Banse, K., \& Anderson, G. C., 1967. Computation of chlorophyll concentration from spectrophotometric readings. Limnol. Oceanogr. 12, 696-697.

Barnes, C. A., Duxbury, A. C. \& Morse, B. A., 1972. Circulation and selected properties of the Columbia River effluent at sea. In: The Columbia River estuary and adjacent ocean waters: bioenvironmental studies. Ed. by A. T. Pruter \& D. L. Alverson. Univ. of Washington Press, Seattle, 41-80.

Creitz, G. I. \& Richards, F. A., 1955. The estimation and characterization of plankton populations by pigment analyses. III. A note on the use of "Millipore" membrane filters in the estimation of plankton pigments. J. mar. Res. 14, 211-216.

Curl, H. Jr. \& Small, L. F., 1965. Variations in photosynthetic assimilation ratios in natural marine phvtonlankton cnmmunities. Limnol. Oceanogr. 10 (Suppl.), R 67-R 73.

Dixon, W. J. (Ed.), 1970. BMD-Biomedical computer programs, X-series supplement. University of California Press, Los Angeles, 260 pp. (Univ. Calif. Publs Automatic Computation 3. .)

Dunstan, W. M., 1973. A comparison of the photosynthesis-light intensity relationship in phvlogenetically different marine microalgae. J. exp. mar. Biol. Ecol. 13, 181-187.

Glooschenko, W. A., Curl, H. Jr. \& Small, L. F.. 1972. Diel periodicity of chlorophyll $\alpha$ concentration in Oregon coastal waters. J. Fish. Res. Bd Can. 29, 1253-1259.

Hameedi, M. I., 1974. Ouantitative studies of phytoplankton and zoodankton and their interrelationships off Washington and Oregon. Ph. D. Diss., Univ. Washington, Seattle, 287 pp.

- 1976. An evaluation of the effects of environmental variables on marine plankton primary productivity by multivariate regression. Int. Revue ges. Hydrobiol. 61, 519-540.

Harris, G. P. \& Lott. T. N. A.. 1973. Lisht intensity and photosynthetic rates in phytoplankton. J. Fish. Res. Bd Can. 30, 1771-1778.

Hartley, H. O., 1961. The modified Gauss-Newton method for the fitting of non-linear regression functions by least squares. Technometrics 3. 269-280.

Jassbv, A. D. \& Platt. T. 1976. Mathematical formulation of the relationship between photosynthesis and lisht for plankton. Limnol. Oceanogr. 21, 540-547.

Lindeman, R. L., 1942. The trophic-dynamic aspect of ecology. Ecology 23, 399-418.

Nihoul, J. C. J., 1975. Apolication of mathematical models to the studv, monitoring and management of the North Sea. In: Ecological modeling. Resources of the Future, Inc., Washington, D. C., 135-147.

Richards, F. A. \& Thompson, T. G., 1952. The estimation and characterization of plankton populations by pigment analysis. II. A spectrophotometric method for the estimation of plankton pigments. J. mar. Res. 11, 156-172.

Ryther, J. G., 1956. Photosynthesis in the ocean as a function of light intensity. Limnol. Oceanogr. 1, 61-70.

- \& Menzel, D. M., 1959. Light adaptation by marine phytoplankton. Limnol. Oceanogr. 4, 492-497.

- \& Yentsch, C. S., 1957. The estimation of phytoplankton production in the oceans from chlorophyll and light data. Limnol. Oceanogr. 2, 281-286.

Small, L. F., Curl, H. Jr. \& Glooschenko, W. A., 1972. Estimates of primary production off Oregon using an improved chlorophyll-light technique. J. Fish. Res. Bd Can. 29, 1261-1267.

Sokal, R. R. \& Rohlf, F. J., 1969. Biometry. Freeman, San Francisco, 776 pp.

Steele, J. H., 1962. Environmental control of photosynthesis at sea. Limnol. Oceanogr. 7, $137-150$.

- \& Baird, I. E., 1961. Relation between primary production, chlorophyll, and particutlate carbon. Limnol. Oceanogr. 6, 68-78.

Steemann Nielsen, E., 1962. Inactivation of photochemical mechanism in photosynthesis. Physiologia P1. 15, 161-171. 
- 1965. On the determination of the activity in $\mathbf{1 4}$ Carbon-ampoules for measuring primary production. Limnol. Oceanogr. 10, 247-252.

- \& Willemöes, M., 1971. How to measure the illumination rate when investigating the rate of photosynthesis of unicellular alga under various light conditions. Int. Revue ges. Hydrobiol. 56, 541-556.

Stevenson, M. M., Schnell, G. D. \& Black, R., 1974. Factor analysis of fish distribution patterns in western and central Oklahoma. Syst. Zool. 23, 202-218.

Strickland, I. D. H., 1960. Measuring the production of marine phytoplankton. Bull. Fish. Res. Bd Can. 122, 1-172.

- 1965. Production of organic matter in the primary stages of the marine food chain. Chemical oceanography. Ed. by J. P. Riley \& G. Skirrow. Acad. Press, London, 1, 477-610.

Taguchi, S., 1972. Mathematical analysis of primary production in the Bering Sea. In: Biological oceanography of the northern North Pacific Ocean. Ed. by A. Y. Takenouti. Idemitsu Shoten, Tokyo, 253-262.

Talling, J. F., 1960. Comparative laboratory and field studies of photosynthesis by a marine planktonic diatom. Limnol. Oceanogr. 5, 62-77.

Unesco (Editor). Determination of photosynthetic pigments, 1966. Unesco, Paris, 69 pp. (Monographs on oceanographic methodology. 1.)

Vinogradov, M. E., Menshutkin, V. V. \& Shushkina, E. A., 1972. On mathematical simulation of a pelagic ecosystem. Mar. Biol. 16, 261-268.

Vollenweider, R. A., 1965. Calculation models of photosynthesis-depth curves and some implications regarding day rate estimates in primary production measurements. Memorie Ist. ital. Idrobiol. 18 (Suppl.), 425-457.

Wallen, D. G. and Geen, G. H., 1971. The nature of the photosynthate in natural phytoplankton populations in relation to light intensity. Mar. Biol. 10, 157-168.

Walsh, J. J. \& Dugdale, R. C., 1972. Nutrient submodels and simulation models of phytoplankton production in the sea. In: Nutrients in natural waters. Ed. by H. E. Allen \& J. R. Kramer. Wiley, New York, 171-191.

Wikum, D. A. \& Wali, M. K., 1974. Analysis of a North Dakota gallery forest: vegetation in relation to topographic and soil gradients. Ecol. Monogr. 44, 441-464.

Winter, D. F., Banse, K. \& Anderson, G. C., 1975. The dynamics of phytoplankton blooms in Puget Sound, a fiord of the northwestern United States. Mar. Biol. 29, 139-176.

Author's address: Dr. M. J. Hameedi

Science Applications, Inc.

$2760-29$ th street, Suite 209

Boulder, Colorado 80302

USA 